Article

\title{
Engaging the Public in Policy Research: Are Community Researchers the Answer?
}

Liz Richardson

School of Social Sciences, University of Manchester, Oxford Road, Manchester, M13 9PL, UK;

E-Mail: liz.richardson@manchester.ac.uk; Tel.: +44-161-275-0879

\section{How to Cite this Article}

Richardson, L. (2014). Engaging the Public in Policy Research: Are Community Researchers the Answer? Politics and Governance, 2(1), 32-44.

\section{Copyrights}

(C) 2014 by the author; licensee Cogitatio (Lisbon, Portugal). This article is licensed under a Creative Commons Attribution 4.0 International License (CC BY).

\section{Published by:}

\section{COGITATIO}

www.cogitatiopress.com

\section{About the Journal}

Politics and Governance is an innovative new offering to the world of online publishing in the Political Sciences. An internationally peer-reviewed open access journal, Politics and Governance publishes significant, cutting-edge and multidisciplinary research drawn from all areas of Political Science.

www.cogitatiopress.com/politicsandgovernance

\section{Editors-in-Chief}

Professor Andrej J. Zwitter, Faculty of Law, University of Groningen, The Netherlands

Professor Amelia Hadfield, Department of Psychology, Politics and Sociology, Canterbury Christ Church University, UK

\section{Managing Editor}

Mr. António Vieira, Politics and Governance, Cogitatio Press, Portugal 
Article

\title{
Engaging the Public in Policy Research: Are Community Researchers the Answer?
}

\author{
Liz Richardson \\ School of Social Sciences, University of Manchester, Oxford Road, Manchester, M13 9PL, UK; \\ E-Mail: liz.richardson@manchester.ac.uk; Tel.: +44-161-275-0879
}

Submitted: 2 December 2013 | In Revised Form: 10 March 2014 | Accepted: 24 March 2014 |

Published: 14 April 2014

\begin{abstract}
A case has been made for engaging the public in scientific research as co-producers of knowledge. These arguments challenge elite models of policy research and suggest the need for an ambitious expansion of more inclusive scientific public policy research. Enabling the public to be meaningfully involved in complex policy research remains a challenge. This paper explores a range of attempts to involving the public in public policy research. It uses a binary framing to typify some key debates and differences in approaches between community-based participatory research, and citizen science. Approaches to communitybased participatory research in the social sciences offer a set of engagement principles which are an alternative to an elite model of policy research. Citizen science offers a focus on the use of scientific methods by lay people, but this approach is currently under-utilized in public policy research and could be expanded. How could the strengths of each be more fully integrated and harnessed? A case study of community policy research is presented, in which an attempt was made to use a more fully integrated approach in a local policy context, identifying the potential and challenges. Based on a framework of three features of democratic and scientific policy research, it argues that more public participation in public policy research would be helped by more attention to the strengths of the democratic potential emphasised by participatory community-based research, alongside the potential of scientific robustness emphasised by citizen science. One conclusion drawn is that a professional and scientific orientation to public policy research can be retained without necessarily being professionally dominated. Research methods and skills are tools to which more people outside the profession could have access, if academics facilitate the process of democratization of policy research.
\end{abstract}

\section{Keywords}

citizen science; community-based participatory research; policy research; public participation; public policy

\section{Issue}

This article is part of a regular issue of Politics and Governance, edited by Professor Andrej J. Zwitter (University of Groningen, The Netherlands) and Professor Amelia Hadfield (Canterbury Christ Church University, UK).

(C) 2014 by the author(s); licensee Cogitatio (Lisbon, Portugal). This article is licensed under a Creative Commons Attribution 4.0 International License (CC BY).

\section{The Challenges of Democratizing Policy Science}

As a society we face a number of public policy challenges, from citizens' increasing expectations of government and public services at a time of pressure on public spending, to major crises of urban and environmental sustainability. Multiple new uncertainties in public life and the pluralisation of spaces for political dialogue and protest suggest the need for new participatory approaches to policy challenges. Internationally, there are signs of growing support for research projects across the natural and social sciences which involve citizens in some way. ${ }^{1}$ Public participation in

\footnotetext{
${ }^{1}$ Thousands of universities across America are committed up to improve their practice of civic engagement and engaged scholarship, for example through the Campus Compact Initiative, and Community-Campus Partnerships for Health. The UK has a National Co-ordinating Centre for Public Engagement which promotes Beacons of engagement practice, and policy
} 
policy research and analysis is part of a 'more open and democratic process of knowledge production' (Brock \& McGee, 2002, p. 8). There is now a growing body of work which argues for a wider role for various publics in scientific research as co-producers of knowledge (Nutley, Walter, \& Davies, 2007; Armstrong \& Alsop, 2010; Martin, 2010).

A pressing case has been made for the democratization of the policy sciences (DeLeon, 1994). One irony of political science research on citizen participation in the production of public goods is just how little participation there is in that research. This is a long-standing dilemma of the 'paradox' of sciences which 'owe their origins to practice' but which rarely produces knowledge enhance that practice (Dunn, 1996, p. 255). Understanding the evidence-policy gap as not a problem of knowledge transfer, but of knowledge production, offers a route to engaged scholarship (Boyer, 1996; van de Ven, 2007). This builds on a longer tradition of engaged scholarship, following Lasswell, to overcome disconnection between analysis and politics (Bennett \& Roberts, 2004; Boud, Keogh, \& Walker, 1985; Kolb, 1984; Robb, 2002; Schön, 1983). Yet, policy research and analysis by both professional and academic elites continues to be dominated by what Wagenaar describes as a 'high-handed, technocratic style of policy making [...] in which the citizens [...] are [...] disenfranchised from the governance of their own environment' (Wagenaar, 2007, p. 22). How to enable the public to be meaningfully involved in research which contributes to complex policy discussions remains a serious challenge. Who should policy-makers listen to-policy scientists with robust evidence, or citizens' grassroots insights? How could an ambitious expansion of more inclusive and high quality scientific public policy research be achieved?

The normative case for making our own discipline more exemplary of the democratic values it often advocates is seen here as relatively unobjectionable. How this actually works is a more complex challenge. This article explores a range of attempts to involving the public in public policy research. It focuses on approaches which typify some of the debates and key differences: community-based participatory research;

and community engagement is one of the metrics for grading of universities, which also affect funding allocations. Participatory research approaches, such as Participatory Action Research (PAR) developed originally in the global south are also migrating to marginalized communities in the global north through community-based participatory research projects across the UK, US and Europe, with examples such as the Detroit Community-Academic Urban Research Centre based in University of Michigan School of Public Health. Numerous networks exist such as the Global Alliance for CommunityEngaged Research, Living Knowledge (an international network of 'Science Shops'), and other country-based groupings. and citizen science. It uses this binary framing to argue that the many positive moves towards democratization of research and policy knowledge are hampered by divides within the scientific community on approaches to public participation. Approaches to communitybased participatory research in the social sciences offer a set of engagement principles which are an alternative to an elite model of policy research. Citizen science offers a focus on the use of scientific methods by lay people, but this approach is currently under-utilized in public policy research and could be expanded. How could the strengths of each be more fully integrated and harnessed?

A case study of community policy research is presented, in which an attempt was made to use a more fully integrated approach in a local policy context, identifying the potential and challenges. Based on a framework of three features of democratic and scientific policy research, one conclusion is that more public participation in public policy research would be helped by more attention to the strengths of the democratic potential emphasised by participatory communitybased research, alongside the strengths of the scientific method emphasised by citizen science.

\section{Strengths and Challenges in Community-Based Participatory Research (CBPR)}

Some of the key strengths of CBPR are that it has created platforms for more democratic research processes, by opening up spaces for the public to participate. ${ }^{2}$ In these ways, CBPR contributes to democratization of research and overcoming an elite-dominated model. CBPR offers a radical critique of more traditional and non-participatory research, as well putting forward positive alternatives for researchers who wish to work in ways which do not compromise their values. These core strengths have seen participatory approaches gain international popularity and become widely used in a range of social science disciplines, including health and social policy, cultural history, anthropology, and sociology.

CBPR is defined by some writers in non-schematic way, and is based instead on a set of principles and values (Minkler, 2004), underpinned by a principle that research is a relationship between equals. Others set

\footnotetext{
${ }^{2}$ Notions of what constitutes the public, communities, citizens, non-professionals, lay people etc, are extremely complex. One issue is who has the power to define these concepts. Even setting firm boundaries between scientists or researchers, and the public or communities, is a troublesome proposal, which neglect the porosity of boundaries. For example, some individuals span boundaries between worlds or roles, such as 'academic-activists' or 'pracademics'. For simplicity's sake, the use of the term public here broadly includes people or groups of people who are primarily based outside recognised academic institutions.
} 
out a continuum of degrees of community power and control over research, from data collection at the lowest end, to identifying research questions at the higher end (Goodson \& Phillimore, 2012). CBPR is considered to be participatory and empowering of participants. Explicit articulations of the locations of power in research are offered (cf. Cornwall \& Jewkes, 1995) proposing a: 'deconstruction of power and the democratization of knowledge such that the experiential knowledge of community members is valued and knowledge that previously was the purview of scholars is accessible physically and intellectually to community participants' (Minkler, 2004, p. 686). CBPR challenges the notion that academic research is 'the exclusive domain of objective scientists' (Goodson \& Phillimore, 2012, p. 8), and so create scope for lay people to be more equal participants in research. In Lindblom and Cohen's (1979) attack on the dominance of professional social inquiry they pose ordinary knowledge, 'common sense, casual empiricism or thoughtful speculation and analysis' (p. 12) as an alternative.

\subsection{Challenges for CBPR Approaches in Policy Research}

CBPR poses critical and much needed questions about inequalities in power and relationships in knowledge production. It is reassuringly consistent to see academic colleagues exemplify the participatory and democratic values promoted by political science in the discipline's own work. However, some leading writers associated with this set of approaches take this logic one step further. They come close to relinquishing a belief in the highest standards of scientific evidence. For example, reclaiming of citizens' and scientists 'cultural rationality', where lay people's cognition is based on 'personal and familiar experiences', in the face of scientists misplaced belief in their own technical rationality and 'faith in empirical evidence and the scientific method' (Fischer, 2005, p. 55). Despite claims by some in this camp to be pro-knowledge rather than anti-science (Cozzens \& Woodhouse, 1995), the concept of cultural- over technical rationality comes dangerously close to a rejection of science per se. This creates a particular issue for policy-orientated research, where controversial, high-risk, and politicallydriven public policy debates demand the ability to make bold claims about knowledge and/or evidence. What suffers in some CBPR approaches is the ability to gain purchase on mainstream public policy audiences because of the failure to overcome the limits of approximate knowledge. Policy research gains from the enhanced democratic potential in CBPR, but arguably can lose traction from the ambivalence around the 'scientific method'.

This challenge to and for CBPR comes with many qualifications. There are many nuanced variations within CBPR approaches. Research and researchers adhere more or less to a broad set of underlying principles. It could best be described as an 'idiom with breadth and elasticity' (Jasanoff, 2004, p. 6). The challenges set out here are clearly not all equally applicable to all pieces of research that would loosely style themselves as somewhere along the CBPR continuum. However, it is possible to see some common threads. One thread is about the relative absence of certain research methods. The literature emphasises the need for appropriate scholarship to transform what, would otherwise be engagement into engaged scholarship (Commission on Community-Engaged Scholarship in the Health Professions, 2005). An argument has been made that CBPR 'is not a method per se but an orientation to research that may employ any of a number of qualitative and quantitative methodologies' (Minkler, 2004, p. 685, emphasis added). However, examples of the 'variety of approaches to research' are 'collaborative inquiry, participatory action research (PAR), feminist participatory research, and action research'. What are missing in this list are some key methods for policy research, particularly field experimental research. ${ }^{3}$ For research which speaks directly to the concerns of public policymakers, a cogent argument has been made elsewhere that methods could and should include experimental designs. ${ }^{4}$ Where there have been exceptions, and experiments have been used, there remain doubts about the legitimacy and ethical position of these methods. For example, innovative work on participatory forms of randomized controlled trials (RCTs) (Katz, Murimi, Gonzalez, Njike, \& Green, 2011), have been critiqued as placing CBPR in a subservient and instrumental position to the RCT (Trickett, 2011).

It could be a relatively simple matter to broaden out the range of research designs and methods used within participatory research to guarantee appropriate scholarship and reliable knowledge for policy use. However, for some advocates of CBPR, their challenges to conventional notions of 'robust science' go deeper than debates about choice of research design. Some participatory approaches are based on a fundamental rejection of 'positivism'. This is a deep thread that can be found in the work of leading writers who are associated with CBPR, or who are cited by those who promote CBPR. These authors included such distinguished academics as John Dryzek, Frank Fischer, Andrew Van de Ven, Peter deLeon, Donald Schön. Indeed, DeLeon (1994), Dryzek (1990), Fischer (1993) and others blame the positivist turn for a tyrannical and anti-democratic stance in policy science. Policy science, they argue, has concentrated on elite-dominated policy processes, and is itself a powerful elite. Arguments have been made against the 'relics of positivism and logical empiricism'

\footnotetext{
${ }^{3}$ For a discussion of experimental methods, see Green (2013).

${ }^{4}$ For example, see discussion in John et al. (2011).
} 
(Kenworthy-U'ren, 2005, p. 361), 'the residual of scientism and positivism in citizen science' (Mueller, Tippins, \& Bryan, 2012, p. 3), and of romanticised notions of scientism (Weinstein, 2012, p. 1). CBPR is said by some to have a strong association with ideas of interpretive social science (Jasanoff, 2004, p. 4). The idiom is grounded in a critical realist philosophy of science (van de Ven, 2007), where a lack of epistemological legitimacy is seen as being derived from knowledge which is isolated from social practices and public participation (Schön, 1995), and knowledge based on positivism.

\subsection{Challenges for CBPR in Democratizing Research}

There is another issue with the democratizing potential of CBPR. Community research is premised on the ideas of culturally situated or local knowledge, and experiential or lived expertise. CBPR is said to improve 'the quality and validity of research by engaging local knowledge and local theory based on the experience of people involved' (Commission on Community-Engaged Scholarship in the Health Professions, 2005, p. 12). Community researchers are seen as having a privileged claim to accessing, generating and interpreting data. In doing this, what frequently results is that community researchers act instead as respondents. There are many examples in practice of positioning of community researchers as both researchers and respondents, e.g. see Institute for Community Research (2007).

Conflation of researcher and respondent roles, and privileged claims for data access, collection and interpretation may paradoxically lead us away from the democratizing impulses of CBPR. At the very least, several troubling issues and dilemmas are raised by this conflation and privileging. Tensions are made explicit in one project which integrated secondary analysis of national quantitative datasets with new primary indepth qualitative data on the links between long-term ill health and poverty. Some of the qualitative data was produced in collaboration with community researchers. An official report on the research (Salway, Platt, Chowbey, Harriss, \& Bayliss, 2007) did not cover methodological challenges of working with community researchers, and the authors outside the main report say that the underlying challenges are 'rarely discussed' (Ismail, Salway, \& Chowbey, 2011a). In presentations about the research process, the project academics identified tensions between community researchers' roles as respondents or researchers as a key complexity and challenge (Salway, Harriss, \& Chowbey, 2006). They pointed to overlaps in roles for the participants as community researchers, community members, and also community leaders or advocates, resulting in the 'underlying challenges' of the participant lacking 'detachment from personal views' and having 'difficulties 'stepping back' and being reflexive'. Lines between the researcher and respondents were 'blurr[ed]' by 'a desire to speak on behalf of their community', and there was 'a tendency to essentialise their own communities and exaggerate the differences between themselves and other 'groups' (Ismail, Salway, Chowbey, 2011b). These would seem to be serious risks to the research process, and even challenge the validity of the data collected, analysed and presented. In a pure academic context, a review which presented these challenges to the objectivity of the research would be rather damming. Full democratization should have the same standards, for example on data quality and analysis, for research done by professionals and research undertaken by communities and citizens. If there are dual standards, one possible consequence is the risk of reinforcing rather than overcoming outside/professional and insider/non-professional divides. Therefore, where community researchers' roles lie between researchers and respondents, there is a danger that they may not be fully empowered as researchers, and recognised as scientists.

CBPR sees community researchers' memberships of respondent groups, and insider status as enhancing research access and the ability to elicit data, (Cornwall \& Jewkes, 1995, p. 14), premised on the idea that the relationship between outsider professional researchers and respondents is 'all too often characterise[d]' by 'mistrust and unfamiliarity' (O'Brien, 2011). Community partners are guarantors of the 'trustworthyness' of the professional researchers (Institute for Community Research, 2007, p. 44). Where snowball sampling via community members' networks was used in one project, it was felt to result in 'the research team [...] acquir[ing] rich information that would be more difficult, if not impossible, with only outside researchers' (p. 60). One question these claims raise is whether participants might be disempowered rather than empowered by a reliance on their group membership or status to elicit valid responses on sensitive subjects rather than being given access to different research methods specifically designed for this purpose? However, another serious challenge is whether claims of privileged access result in better quality research. There have been very few studies which test these ideas empirically. One study used secondary analysis of sample disposition data from two area probability surveys of the same community areas, one involving community interviewers in a fully collegial CBPR study and the other using professional interviewers. Its findings were that there were higher cooperation and lower refusal rates for the CBPR study than data collected by professional interviewers, but that the sample produced by CBPR interviewers overrepresented certain population groups (Rucinski et al., 2011).

In citizen science, one does not necessarily need to be a bee, or a beekeeper, to be a member of the research team. Data collection and analysis protocols are based on scientific research methods, albeit methods that are backed and protected by the monopoly power of the academy. Citizens are amateur scientists rather 
than respondents. What additional strengths are offered to policy research by a citizen science approach?

\section{Strengths and Challenges in Citizen Science in Public Policy Research}

Citizen science, as the term is used here, ${ }^{5}$ and is often popularly used, describes one set of approaches within Public Participation in Scientific Research (PPSR). ${ }^{6}$ Citizen science has typically had the benefits of operating on a large-scale with mass citizen involvement in research, using an empirical and scientific approach to research. Internationally there are now large-scale citizen science projects ranging from involvement in astronomy to ornithology, biochemistry, astronomy, and mathematics. Citizen scientists across STEM subjects are featured as US Government 'Champions of Change'. Citizen science has been dominated by natural science-counting shellfish, bees, water quality, acid rain, birds, weather patterns, stars and planets. Some attributes of research projects 'ideally suited to citizen science' are: 'data collection is labor intensive; quantitative measurements/observations are needed; protocols are well designed and easy to learn and execute; large data sets are needed' (Gommerman \& Monroe, 2012, p. 2). Given this, it is understandable that much of citizen science is with non-human subjects, and non-qualitative work, working outside a policy context or without direct policy engagement.

The scientific methods used in citizen science have much to offer social science disciplines, but have so far been under-utilized in political science and public policy research. Many of the natural science citizen science

\footnotetext{
${ }^{5}$ It is important to note that the term citizen science has been used differently elsewhere. This includes the work of Alan Irwin, e.g. his 1995 book called 'Citizen Science' (Oxon, Routledge), which associates the term with both science which focuses on the concerns of citizens, as well as citizens' contextual knowledges generated outside formal scientific institutions.

${ }^{6}$ Citizen science is used here to refer to projects that would be categorised as contributory projects under one typology of PPSR (Cohn, 2008), which suggests three models: 'Contributory projects, which are generally designed by scientists and for which members of the public primarily contribute data; Collaborative projects, which are generally designed by scientists and for which members of the public contribute data but also may help to refine project design, analyze data, or disseminate findings; and Co-created projects, which are designed by scientists and members of the public working together and for which at least some of the public participants are actively involved in most or all steps of the scientific process.' (p. 11). Other adaptations of this schema add research by professional researchers which is commissioned by communities (termed contractual projects), and, collegial projects where research is conducted by non-credentialed individuals outside of the academy which may or may not be recognised by 'institutionalized science' (Shirk et al., 2012).
}

projects, particularly earth sciences and environmental studies, are directly relevant to public policy. For example, in the field of environmental governance, there are surveys of wildlife conducted by citizens, including one long-standing annual survey of birds in the United States called the Audubon Christmas Bird Count. Organisers of the Bird Count argue on their website that their work has contributed to 'the implementation of policies that safeguard birds, other wildlife and the resources that sustain us all', including 'innovative policies that balance habitat protection with green energy development on millions of acres (National Audubon Society, n.d.). But for many academics that identify themselves as political scientists or policy analysts, citizen science has yet to make the same impact in these disciplines as in the natural sciences. We see very few citizen science projects with human subjects in the social sciences.

\subsection{What Citizen Science Could Learn from CBPR}

However, there remains a key problem with citizen science; it fails to provide a sufficiently empowering process for the citizen participants. Partly, this is because the field has been dominated by what has been called here citizen science, and also known as contributory PPSR projects, where citizens are not fully involved in all aspects of the research process, and where professionals or academics retain overall control. Not all PPSR projects are in the contributory category, and many excellent examples can be found of PPSR research projects towards the 'collaborative' and 'cocreated' end of the citizen science spectrum (Bonney at al., 2009, p. 18). However, some evidence suggests cocreated cases are more exceptional than widespread in PPSR work: 'Most projects labelled citizen science fall into the 'contributory project' model of 'researcher-driven data-collection projects', where scientists ask the question, determine the protocols, do the analysis, and members of the public collect relevant data (Bonney at al., 2009, p. 18). Some have challenged mainstream citizen science because of the lack of full citizen participation in setting research question, developing research designs and methods, analysing data or being credited in publications (Mueller et al., 2012, p. 3). Many in citizen science are mostly transparent about the roles of volunteers as 'field assistants in scientific studies', who 'typically, [...] do not analyze data or write scientific papers' (Cohn, 2008, p. 193). It is argued that many undertake the work unpaid as an everyday volunteering activity (Cohn, 2008). Citizens may choose to participate in the collection of data for scientists as a civic act, which in itself is part of the wider goal of strengthening democracy through civic participation. Many forms of volunteering are still welcome even if volunteers do not participate in organisational governance. However, an empowering approach to 
policy research, as highlighted by CBPR, suggests the involvement of citizen scientists across all stages of the research process, and more equal relationships between citizen scientists and professional researchers.

Going beyond this, there are some more fundamental barriers to promoting more collaborative and co-created PPSR projects. CBPR argues for a deconstruction of power in the research process. A commitment to equality in relationships between citizens or community researchers and professional scientists is seen as crucial. However, framings for PPSR approaches retain power and control over 'science' for professional scientists, and within academic institutions; all the hallmarks of an academic elite-dominated model are implied by the PPSR schema. For example, the insistence on tight delineations between members within the academic profession and those outside it, and the monopoly role of the institution in scientific investigations (Bonney at al., 2009, p. 11). Where research is conducted by non-credentialed individuals outside of the academy, this may or may not be recognised by institutionalized science (Shirk et al., 2012). PPSR fails to overcoming the institutional separation of 'a select group of expert knowers' from 'the lay public' in a more democratic approach to the production of knowledge (Barker, 2004, p. 125). The role of scientist is assumed to be inhabited by a delineated set of professionals, leaving less space for community participants to play meaningful roles in research. If the tools of science are to be fully democratized, then the idea of science as the sole province of the professional scientist needs to be questioned.

\subsection{A Framework for Integrating Strengths from $C B P R$ and Citizen Science Approaches to Research}

How could we use the potential for expansion of public participation suggested by citizen science, maintaining a scientific approach, together with the democratic principles suggested by participatory research, while applying them to research with human subjects on public policy topics? Looking again at what the literatures and approaches might imply, there are several features which have the potential to more deeply integrate the strengths of both sets of approaches for policy research.

First, a commitment to the values and principles of empowerment and participation, and equality in relationships between academics and non-professional researchers, including full co-design at all stages of the research process. Secondly, to do this while also maintaining the primacy of the 'scientific method' over the identity or background of the researcher, and the separation of the community researcher and respondent roles. This requires efforts not to displace one form of knowledge and expertise with another, integrating lived expertise as a form of data in the method, rather than personal experience substituting for the method.
Thirdly, the implementation of these features in public policy research, with human subjects, and a direct policy orientation.

We now turn to a case study of a research project to develop public policy in an English local government. This project attempted to incorporate participatory principles, while maintaining a separation of researchers and respondents and privileging research methods above the identity of the researchers.

\section{Case Study of an Attempt to Use a more Integrated Approach}

The author was the team leader for research to develop healthcare strategy and interventions in a local government area in the North West of England. A local public sector partnership commissioned the work, which was paid for by the local statutory public health body. It was a small project with a budget for the research of $£ 5,000$ which paid for the academic input, which was supplemented by help-in-kind such as staff time from five local government workers, venue costs for team meetings and materials. The project worked with a team of seven community researchers to undertake the work. Efforts were made to put co-design into practice at all stages of the research process for the case study community research project, subsequent to the brief for the work. The community research project was a primarily qualitative study of public perceptions on alcohol misuse to inform the development of policy. It is used here as a revelatory case study of an attempt to use a more fully integrated approach.

\subsection{Methodology}

The methodology for the community research itself is described below as part of the description of the case study. The methodology for the case study was an analysis of documentary material from the research project, including: official documents such as the brief and specification for the project; research team training meeting materials, such as research skills information sheets and facilitator programmes for meetings; minutes of research team meetings and other meetings throughout the project; copies of private correspondence between team members, and between team members and the commissioners. Minutes of the research team meetings were operational documents produced by different members of the team, not including the author, to record discussions, decisions and action points. These documents also included appended verbatim notes of discussions, and observational data recorded by the author. Documentary analysis was then done against the three features of a more fully integrated approach to public engagement in policy science: commitment to empowerment principles; primacy of the method and separation of re- 
spondent and researcher roles; and direct policy orientation. The use of the community research project as a case study was conducted solely by the author, and had no participatory element.

The next sections present a summary descriptive account of the case study research project, before turning to an exploration of how the project attempted to implement a participatory, empowering yet scientific piece of policy-focused research.

\subsection{Case Study Description}

The overall aim of tackling alcohol harm research was to develop feasible and concrete proposals for public, voluntary and community sector services on the development of behavioural change techniques to address harm from alcohol misuse. The research was intended to gather detailed and qualitative public perception data to supplement existing local datasets, which covered administrative data such as numbers of alcoholrelated hospital admissions. The local public sector partnership which commissioned the work used existing statistics to identify a geographical area of around 2,000 households in a disadvantaged neighbourhood that experienced higher than average levels of severe alcohol-related problems. Open advertising was used to recruit community members from the neighbourhood to be volunteer community researchers. The research team was made up of the community researchers, an academic (the author) and local government workers. A purposive sample of groups at risk of experiencing harm from alcohol was identified by the research team, based on health data and known risk factors. Qualitative data was gathered by the team in four ways. First, vox pop interviews, which are short qualitative 'mini-interviews', often conducted on the street. Seventy four vox pop interviews were completed across seven public locations. The vox pop interviews were used to recruit a smaller sample for indepth qualitative interviews. A total of eleven in-depth interviews were completed. The third method was selfcompletion postcards which were handed out in specific residential locations at different times and days of the week, with 'drop boxes' placed nearby for completed responses. A total of eighty-five completed postcards were collected. Finally, the fourth method was two focus groups, one with five younger people, and the other with parents of young children. After collation, a sample of the data was blind coded, the codes reconciled to create the coding framework, leading to a thematic analysis of the data. A draft of the emerging findings was tested in a practitioner workshop. An amended final report was presented by the research team to the partnership which had commissioned the research, which was also the decision-making body for the local alcohol harm reduction strategy.

\subsection{Analysis of the Case Study for Public Engagement in Public Policy Research}

In itself, the research project is relatively unremarkable, although it did yield some powerful insights into low-income residents' perceptions about a personal and sensitive issue. What is more noteworthy are the attempts made to address some of the issues identified earlier in the debates between citizen science and community-based participatory research. Using the framework identified earlier, we now explore the project in terms of the implementation of three features of democratic and engaged public policy research.

\subsubsection{Empowerment, Equality of Relationships and Co- Design of Research}

The community researchers were members of marginalized groups which were typically absent from traditional policy consultation exercises in the neighbourhood. The individuals had chosen to take part in the project on a voluntary basis. Recruitment advertisements were circulated to a range of local citizen organisations, public forums, and in public locations. In the recruitment material, a basic volunteer role description was outlined. People who expressed an interest were then invited to a taster session, which was used to engage participants in the substantive content of the research, and discuss possible sampling approaches. Of the twenty citizens who attended the taster sessions, 12 then signed up for the project, of whom seven then participated to completion. Five of the community researchers had never been involved in any researchrelated activity previously; two had done some relevant work in adult education courses but not a primary research project, research design or conducting fieldwork. At least three had personal experience of alcohol harm and/or poor mental health. At least two of the team had problems with basic skills (functional literacy and numeracy). All were from the study neighbourhood. Each member of the core community researcher team was supported by a local government worker (five support workers in total) who were also part of the research team.

A commitment to the values of empowerment was also demonstrated through the provision of qualifications. Six of the seven community researchers completed a qualification in research skills which was awarded through a quality-assured accreditation system for informal or community-based education that exists in the UK. ${ }^{7}$ Five of the local government workers who were part of the research team gained assessor status for community-based qualifications. Some of the

\footnotetext{
${ }^{7}$ The accrediting body is called the National Open College Network.
} 
team also gave a presentation to undergraduate students at the University as part of students' research skills training as a form of reverse service learning.

Equality in relationships was facilitated in two key ways: the creation of a standard research team; and attempts at co-design at all stages of the research process subsequent to the initial specification by the client. All participants were full members of the research team, with the academic as research team leader as would be usual in a research project with a lead Project Investigator. However, the other team members had co-investigator status, rather than being the equivalent of research assistants. Six research team training meetings were used to provide basic training on research skills, and to design or complete each stage of the research as a group. Efforts were made to put co-design into practice in all stages of the research project. Codesign or co-production was used to: design the research and agree research methods; select the sample; draw up detailed research questions; select suitable study sites and access to respondents; create and adapt the research instruments; complete the fieldwork; develop the coding framework and analyse the data; prepare the findings, recommendations and presentations to the policy-makers. All members of the team conducted fieldwork. Some co-design was achieved using simple but generic techniques. For example the specific research questions were the result of an individual brainstorming exercise, and team discussion. Research skills training and other facilitation was also provided to help make more technically challenging aspects of the co-design a genuine and meaningful process for inexperienced community researchers and local government workers. For example, to introduce the concepts of coding and thematic analysis, a session involved the group interpreting and coding lyrics from popular music songs about alcohol harm. Following this introduction, all members of the research team worked in pairs to blind code a sample of the data across all four research methods. ${ }^{8}$ The coding framework was then created by reconciling the six sets of codes as a group in one of the team meetings using a simple chart. During a team meeting, the team then spilt into smaller groups to include members with more or less advanced literacy skills. Each group fully coded a section of the data. The coded data was used to create a thematic analysis. Participatory research has less commonly achieved full co-design in the initial and latter stages of research, including analysis and writing up (Beebeejaun, Durose, Rees, Richardson, \& Richardson, 2013). 'Song lyrics' training meant that the coding framework and coding of data leading to the analysis

${ }^{8}$ Some pairs were made up of two community researchers; others were one community researcher and one local government worker; one team was two local government workers. was a genuinely collective effort. However, the project team leader (i.e. the academic) took the majority of responsibility for writing up the analysis done by the team. Divisions of labour for writing up research are complex on any project, and this may or may not represent a power inequality for the case study. However, it is the case that this gap was not adequately addressed in the case study. Although, the drafts were subsequently checked verbally with the team, and circulated for written comments. Amendments for the final report were agreed verbally by the whole team after the feedback from the workshop. Verbal presentations on the findings were given by community members of the research team.

The basic specifications for the project were not codesigned with citizens. Pre-project contract negotiations between the academic and commissioners highlighted their concerns about this element of the participatory ethics of project. Some commissioners felt that there was a tension between the co-design principles of the project and the constraints of the brief and commission. Specifically, they were unsure whether it was acceptable to recruit the research team on the basis of a pre-set specification for the research topic (alcohol harm) and research aims (gather perception data to generate policy recommendations on behaviour change). One resolution was to make these specifications transparent in the recruitment materials and taster sessions. An effective counter-argument was that many 'professional' academic pieces of research are equally constrained by funders' specifications and research interests. Employing the principles of equal relationships meant trusting that the community members of the team would be able to understand and appreciate this reality. Minutes of the taster sessions show that participants had been attracted by the content of the brief as much as the opportunity to develop new skills and engage in voluntary work, and were therefore comfortable with the constraints of the project.

Beyond their participation in producing the report of the project, the community researchers team declined an offer of co-producing and co-authoring this academic output. Their stated reasons for this were that they felt their time would be more productively invested in the other follow-up activities such as the dissemination of project findings through a community play, new deliberative research through a citizens' jury, and exploring income-generating opportunities for the team to work as a research consultancy.

\subsubsection{Primacy of the Method and Separation of Researchers and Respondent Roles}

Research team training sessions were structured to maintain the primacy of the method. In one session, an exercise to identify potential samples first drew on the 
community researchers' existing local knowledge of groups at risk or experiencing harm from alcohol, and then tested this against existing secondary analysis of local administrative health data. Their local knowledge was not the basis for the sample selection, but instead was used as a way of applying research methods training. The idea behind this was to build research skills in an empowering way by grounding the discussion in people's existing experiential assets. All of the possible samples generated by the group also appeared in the health data as priority groups for existing alcohol harm (e.g. mortality rates and hospital admissions). However, as the group reviewed the available data, they found that it only included adults over 18 years, and was based on indicators which measured harmful outcomes rather than risk factors. A research aim was to identify targets for preventative work, and other data and intelligence held by the local government team also suggested that children and young people from this deprived neighbourhood were a high-risk group. Therefore, a result of the data review was an amended sample for the research. The sample consisted of three groups either currently at most risk of harm from alcohol, and/or where preventative early intervention could be effective: younger people (teenagers and young adults) aged between approximately 13 to 25 years; parents of younger children; isolated and/or vulnerable single older people (over age 50 years).

Another approach used to maintain scientific methods, given the skills and capacities of the group, was the use of projective techniques in the research instruments in the qualitative fieldwork. Projective techniques are broadly defined as the presentation of ambiguous stimuli to respondents. They include use of materials such as video clips, photographs, or objects to prompt discussion, as well as qualitative instruments where respondents undertake self-completion exercises. The project used projective techniques in the vox pop interviews, postcards, and focus groups. Examples of the specific projective techniques included questions in the vox pop interviews which asked respondents to complete the sentences 'Drinking is enjoyable because...' and 'Drinking causes harm because...'. The self-completion postcards requested written responses to an open ended question. Postcards invited people to 'anonymously contribute a secret about alcohol. Your secret can be a: regret; fear; betrayal; confession; desire; or childhood humiliation. Reveal anything as long as it's true'. Focus groups used photographs and images of people drinking alcohol to prompt discussion.

Conventionally, these techniques are used because of their advantages in eliciting open responses from respondents. For the purposes of community research, they also had the advantage of being accessible for relatively inexperienced researchers. They offered a simplified and easy to execute set of research protocols. These research instruments did not require sophis- ticated literacy skills, or rely too heavily on individual researchers' ability to phrase appropriate questions. Therefore, they helped to reduce the risk of inconsistency in the conduct of fieldwork across different researchers. In comparison, the in-depth semi-structured interviews demanded higher levels of literacy and qualitative research skills. To address this, several measures were taken, all of which were more time- and technology-intensive for the project. Additional intensive research skills training was completed by team members undertaking this method. Interviews were conducted by phone, and could therefore be recorded, with the recording used to double-check the transcribed handwritten notes. Technology was arranged that allowed two interviewers to conduct interviews to overcome residual research skills and literacy issues.

Throughout the project, the issue of the separation of researcher and respondent roles arose in different symptomatic ways. There were several ways in which the community researchers themselves appeared to drive for a clear separation of roles, and also some suggestions that the commissioners wanted to push them towards being respondents. For example, early in the project a seemingly minor debate in the team meetings was about how the researchers would identify themselves during fieldwork. A decision was reached by the team that all members would be referred to as have an institutional affiliation as 'University of $X$ ' researchers. The community participants in particular did not want to be identified as local residents, but as researchers, and requested University-branded identification badges. Community researchers also were reluctant to conduct fieldwork in parts of the neighbourhood closest to where they lived, as they felt their familiarity with the people and place could be a hindrance to getting good quality data, rather than a help. In response, fieldwork was allocated to study sites outside the community researchers' immediate home location.

Most crucially, initial attempts by the commissioners to place community researchers in the position of respondents were rejected by the community researchers on the grounds that this would poor quality research, based on a small and biased sample. Their personal interests and motivations were to investigate wider community perspectives.

It was more challenging to maintain the separation of roles in the later stages of the project. Despite efforts to focus policy discussions on the research findings and recommendations, the commissioning partnership was ambivalent, and sought to focus on the community researchers' views as respondents, rather than focusing on the data. Policy discussions veered between the content of the research report, and questions about the personal experiences of individual community researchers. This switching between anecdote and evidence can also be seen in policy discussions be- 
tween decision-makers and professional academic researchers; it is not peculiar to community research, but is equally problematic for policy research.

\subsubsection{Public Policy Research and Policy Engagement}

One of the challenges was to design methods that combined some of the features of citizen science in the natural sciences with research with human subjects. For example, inexperienced non-professional researchers collecting sensitive and personal data from field situations using easy to learn and execute protocols. In the alcohol research, the methodology was designed specifically to address this challenge. For example, the projective techniques were effective in eliciting further qualitative material of the most sensitive nature. Selfcompletion postcards yielded some of the richest and most personal data, with in-depth accounts of childhood abuse, family violence, personal stigma and other issues. With a very simple protocol of a request to complete the postcard, it reduced the level of complex fieldwork skills needed to generate quality data on this topic.

Having a commissioned project specifically aimed at developing policy recommendations anchored the research into an ongoing public policy discussion, which included a formal presentation of the findings and recommendations to the commissioners. However, being commissioned is no guarantee that evidence will be heard or used by policy-makers, as there are many barriers (Richardson, 2013). Additional meetings were held with one member of the commissioning body employed by the organisation which had provided funding for the research. These meetings, held during the research design stage and in the early development of findings resulted in the commissioner then advocating for the research to the wider group of decisionmakers inside and outside of formal meetings.

Another strategy used by the team in the case study project was to test and refine draft findings with intended policy and practice recipients. The brief for the research was to develop recommendations for interventions by public and voluntary sector organisations. The team was directed by the client to focus on specific organisations that had already agreed in principle to deliver alcohol harm reduction action plans. Therefore, a workshop with service providers across sectors was used to shape the findings into priority policy recommendations which were likely to find purchase with the organisations that would be asked to implement them. It involved a group of around 25 people who were paid professionals as well as voluntary practitioners from a wide range of services, including specialist alcohol services, family services, front-line neighbourhood services e.g. the police and services for young people. The service providers included organisations in public, voluntary and community sectors. In the workshop participants assessed each of the research findings in relation to relevance and salience to their work, and how effectively the issue was being dealt with by their service. These responses were plotted using a two way matrix with each service placing their provision in the appropriate quadrant on a chart. Of the ten key findings some presented more of a challenge to existing thinking by professionals, while other reinforced what was already known. Reactions from practitioners in the workshop were that all of the findings were salient, and were the basis for priorities for action. These stark findings on the inter-generational effects of alcohol harm gave added impetus to practitioners already moving towards 'whole family' approaches rather than working separately with individual family members. Fresh insights from the research included the finding that it was possible to get some residents in the neighbourhood to talk openly about sensitive and personal alcohol issues, contrary to the original pessimistic view of professionals that this would not be achievable. Recommendations arising from the findings were amended based on feedback from the workshop.

Following this iterative process, the report and recommendations were presented by the whole team to the commissioners and decision-makers. They accepted the longer list of recommendations for action, but amended the ordering of policy priorities. They also then agreed to invest further resources in community research approaches, by commissioning an adapted citizens' jury-method to explore policies on health eating. The statutory public health organisation also commissioned the findings from the alcohol research to be made into a play, with community members as actors, to be performed in the locality.

\section{Conclusions}

Echoes of Lindblom and Cohen's 1979 critique of elite models of research can be heard in current debates between different approaches to public engagement in science. They are framed here as a binary between the strengths of, and challenges for, both citizen science and CBPR. One key conclusion drawn is that a professional and scientific orientation to social inquiry, or in this case public policy research, can be retained without necessarily being professionally dominated or professionalized. Research methods and skills are tools to which more people outside the profession could have access, if we as professionals facilitate the process of democratization of policy research.

An argument has been made for the implementation of three core features of a more fully integrated approach to public engagement in policy science: commitment to empowerment principles; primacy of the method and separation of respondent and researcher roles; and direct policy orientation. How to 
translate debates about epistemology and principles into practice is an area for further discussion. Expanding this type of research requires other changes, including to the infrastructure for ethical approval and peer review which is currently structured around the academic profession and disciplines. This is a case study about participatory research that has been produced with permission, but without participation of the original research team. A desire to produce on peer reviewed journal article outputs is not necessarily shared with such fervour by our community and practitioner partners. The rest of the research team in the case study accepted the value of peer review as a guarantor of quality, and understood its reputational benefits. In this case, their astute recognition of a powerful academic incentive structure for publication meant they were able to prioritise other activities. It would be interesting to see what trade-offs different parties would have made in different circumstances. For example, if alternative formats for academic outputs such as drama were more widely accepted in academia, or if peer review was structured differently. More broadly, this discussion highlighted the presumption of a hierarchy of outputs from research, which privileges outputs which are perhaps more obviously suited to the further academic careers and the academy, rather than achieve a broader set of personal or social objectives for those inside and outside Universities.

Another issue is that part of the nervousness around PPSR-style approaches has been a sense that if citizens are merely research assistants rather than privileged respondents, then they are at risk of exploitation. One attraction to commissioners of the community researchers in the alcohol project was that the project had fewer cash costs than a conventionally conducted project, with estimates of between $£ 20,000$ and $f 25,000$ savings in this case. Plans to generate salaries for the community researchers by creating a not-for-profit research consultancy business were some way off being developed. However, some of those who have raised the issue of 'mass exploitation' themselves agree this is a rather crude framing, and wish to 'capture another side [...] rarely remarked upon [...] strong feelings of love and appreciation between many citizen scientists and the [research] community they are serving' (Weinstein, 2012, p. 1).

Beyond these operational issues, the potentialities are unlikely to be realized in the absence of a commitment by academics to a fuller integration of the principles of both empowerment of citizens, and scientific empirical policy research. Our starting point was the complex ongoing challenge of how to open up academic research to include citizens in meaningful ways. More needs to be done to persuade academic elites that policy research could and should look beyond academia for help in creating robust policy-relevant knowledge. However, well-intentioned attempts to recognise the value of people's lived experience and experiential expertise could, perversely, reinforce the exclusion of citizen researchers from professionals. Even those who claim that academics need to acknowledge their own inherent biases and forms of 'truth' as partial do not advocate that professional researchers simply rely on their own experiences for data. Re-visiting Lindblom and Cohen's critique, 'common sense' abilities of ordinary people could also help them to perform research to a good standard. Citizens' impulses towards 'casual empiricism', where they exist, could be directed towards more formalized empirical public policy research. 'Thoughtful speculation' is an analytical skill which has the potential to be transformed into scientific analysis using data. In these ways, public participation in public policy research could gain expand and gain strength, without either losing its integrity.

\section{Acknowledgements}

Funding for the case study research was provided through Stockport Council, working on behalf of its public sector partners. The community research work was supported by a dedicated team of forward-thinking officers in Stockport Council, as well as the partners involved in the neighbourhood strategy board. Special thanks go to the community researchers for their professionalism, consistent dedication, research insights, and humour.

\section{Conflicts of Interest}

The author declares no conflict of interest.

\section{References}

Armstrong, F., Alsop, A. (2010). Debate: Co-production can contribute to research impact in the social sciences. Public Money and Management, 30(4), 208-210.

Barker, D. (2004). The scholarship of engagement: A taxonomy of five emerging practices. Journal of Higher Education Outreach and Engagement, 9(2), 123-137.

Beebeejaun, Y., Durose, C., Rees, J., Richardson, J., \& Richardson, L. (2013). 'Beyond text': Exploring ethos and method in co-producing research with communities. Community Development Journal, 49(1), 37-53.

Bennett, F., \& Roberts, M. (2004). From input to influence: Participatory approaches to research and inquiry into poverty. York, UK: JRF.

Bonney, R., Ballard, H., Jordan, R., McCallie, E., Phillips, T., Shirk, J., \& Wilderman, C. C. (2009). Public participation in scientific research: Defining the field and assessing its potential for informal science education. Washington DC, USA: Center for Advancement of Informal Science Education. 
Boud, D., Keogh, R., \& Walker, D. (1985). Reflection: Turning experience into learning. London, UK: Kogan Page.

Boyer, E. L. (1996). The scholarship of engagement. Journal of Public Outreach, 1(1), 11-20.

Brock, K., \& McGee, R. (2002). Knowing poverty: Critical reflections on participatory research and policy. Abingdon, UK: Routledge.

Cohn, J. P. (2008). Citizen science: Can volunteers do real research? BioScience, 58(3), 192-107.

Commission on Community-Engaged Scholarship in the Health Professions (2005). Linking scholarship and communities: Report of the Commission on Community-Engaged Scholarship in the Health Professions. Seattle, USA: Community-Campus Partnerships for Health.

Cornwall, A., \& Jewkes, R. (1995). What is participatory research? Social Science and Medicine, 41(12), 1667-1676.

Cozzens, S., \& Woodhouse, E. (1995). Science, government and the politics of knowledge. In S. Jasanoff, G. Markle, J. Petersen \& T. Pinch (Eds.). Handbook of Science and Technology Studies (pp. 533-553). London, UK: SAGE Publications.

DeLeon, P. (1994). Reinventing the policy sciences: Three steps back to the future. Policy Sciences, 27, 77-95.

Dryzek, J. S. (1990). Discursive democracy: Politics, policy, and political science. New York, USA: Cambridge University Press.

Dunn, W. N. (1996). Policy reform as arguments. In F. Fischer \& J Forester. The Argumentative Turn in Policy Analysis and Planning (pp. 254-290). Durham, NC, USA: Duke University Press.

Fischer, F. (1993). Citizen participation and the democratization of policy expertise: From theoretical inquiry to practical cases. Policy Sciences, 26(3), 165187.

Fischer, F. (2005). Are scientists irrational? Risk assessment in practical reason. In M. Leach, I. Scoones \& B. Wynne (Eds.). Science and Citizens: Globalization and the Challenge of Engagement ( $\mathrm{pp}$. 54-65). London, UK: Zed Books.

Gommerman, L., \& Monroe, M. C. (2012). Lessons learned from evaluations of citizen science programs. Gainseville, FL, USA: University of Florida.

Goodson, L., \& Phillimore, J. (2012). Community research for participation: From theory to method. Bristol, UK, Policy Press.

Green, D. P. (2013). Breaking empirical deadlocks in the study of partisanship: An overview of experimental research strategies. Politics and Governance, 1(1), 6-15.

Institute for Community Research (2007). Case studies in community-based collaborative research. Hartford, USA: Institute for Community Research.

Ismail, M., Salway, S., \& Chowbey, P. (2011a). Community researchers: experiences and underlying challenges.
Retrieved from http://www.methods.manchester.ac. uk/events/2011-03-11/Ismail-Salway-Chowbey.pdf

Ismail, M., Salway, S., \& Chowbey, P. (2011b). Community researchers (CRs) methodological issues and challenges. Retrieved from http://www.methods.manchester. ac.uk/events/2011-03-11/slides/ismail.pdf

Jasanoff, S. (2004). States of knowledge: The coproduction of science and social order. London, UK: Routledge.

John, P., Cotterill, S., Moseley, A., Richardson, L., Smith, G., Stoker, G., \& Wales, C. (2011). Nudge, nudge, think, think: Experimenting with ways to change civic behaviour. London, UK: Bloomsbury Academic.

Katz, D. L., Murimi, M., Gonzalez, A., Njike, V., \& Green, L. W. (2011). From controlled trial to community adoption: the multisite translational community trial. American Journal of Public Health, 101(8), e17-e27.

Kenworthy-U'ren, A. (2005). Toward a scholarship of engagement: A dialogue between Andy Van de Ven and Edward Zlotkowski. Academy of Management Learning and Education, 4(3), 355-362.

Kolb, D. A. (1984). Experiential learning: Experience as the source of learning and development. Englewood Cliffs, NJ, USA: Prentice Hall.

Lindblom, C. E., \& Cohen, D. K. (1979). Useable knowledge: Social science and social problem solving. New Haven, СT: Yale University Press.

Martin S. (2010). Co-production of social research: Strategies for engaged scholarship. Public Money and Management, 2010; 30(4), 211-218.

Minkler, M. Ethical challenges for the "outside" researcher in community-based participatory research. Health Education and Behavior, 31(6), 684697.

Mueller, M., Tippins, D., \& Bryan, L. (2012). The future of citizen science. Democracy and Education, 20(1), 1-12.

National Audubon Society (n.d.). About Us. Retrieved from http://www.audubon.org/about-us

Nutley, S. M., Walter, I., \& Davies, H. T. O. (2007). Using evidence: How research can inform public services. Bristol, UK: Policy Press.

O’Brien, M. (2011). Peer research for community evaluations: What can accreditation offer? Retrieved from http://www.evaluation.org.uk/ckfinder/user files/files/evaluator_Markobrien.pdf

Richardson, L. (2013). Putting the research boot on the policy-makers' foot: Can participatory approaches change the relationship between policy-makers and evaluation? Social Policy and Administration, 47(4), 483-500.

Robb, C. M. (2002). Can the poor influence policy? Participatory Poverty Assessments in the developing world (2nd ed.). Washington DC, USA: IMF and the World Bank.

Rucinski, D., Davis, R., Gomez, G., Flores, J., Perez, I., \& Zanoni, J. (2011). An approach to assessing data 
quality in an area probability survey using CBPR. Health Promotion Practice, 12(5), 704-712.

Salway, S., Harriss, K., \& Chowbey, P. (2006). Researching locality with community researchers: putting longterm illness in context. Retrieved from http://www.reallifemethods.ac.uk/events/workshops /localities/localities-salway-harriss.pdf

Salway, S., Platt, L., Chowbey, P., Harriss, K., \& Bayliss, E. (2007). Long-term ill health, poverty and ethnicity. York, UK: Joseph Rowntree Foundation.

Schön, D. A. (1983). The reflective practitioner. New York, USA: Basic Books.

Schön, D. A. (1995). The new scholarship requires a new epistemology. Change, 27(6), 26-35.

Shirk, J. L., H. L. Ballard, C. C. Wilderman, T. Phillips, A. Wiggins, R. Jordan, E. McCallie, M. Minarchek, B. V. Lewenstein, M. E. Krasny, \& Bonney, R. (2012). Public participation in scientific research: A framework for deliberate design. Ecology and Society, 17(2), art 29.

Trickett, E. J. (2011). Community-based participatory research as worldview or instrumental strategy: is it lost in translation(al) research? American Journal of Public Health, 101(8), 1353-1355.

van de Ven, A. H. (2007). Engaged scholarship: A guide for organizational and social research. Oxford, UK: Oxford University Press.

Wagenaar, H. (2007). Governance, complexity, and democratic participation: How citizens and public officials harness the complexities of neighborhood decline. American Review of Public Administration, 37(1), 17-50.

Weinstein, M. (2012). Schools/citizen science: A response to "The future of citizen science". Democracy and Education, 20(1), 1-3.

\section{About the Author}

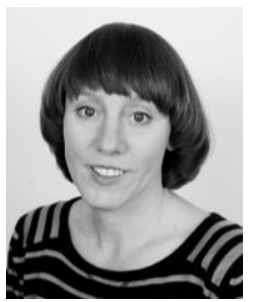

\section{Dr. Liz Richardson}

Liz Richardson is a Senior Lecturer in Politics at the University of Manchester. She conducts research on civic participation, governance and accountability, local politics, public services, and public policy. She has an interest in methodological innovation including participatory research approaches and experimental methods. Liz co-edits the journal Local Government Studies, which celebrates its 40th anniversary in 2014. She also contributes to the work of practitioner partners, including UK-based charities: the National Communities Resource Centre; the National Association of Neighbourhood Management. 